\title{
EDITORIAL
}

\section{Tematizaciones éticas para el buen gobierno}

\section{Dr. Jaime Rodríguez Alba}

UNIR (Universidad Internacional de la Rioja), España; Universidad Siglo 21, Argentina

En general, un buen gobierno en términos finalistas es aquél que proporciona más libertad al ser humano, no aquel que le trata como un menor de edad al que se le busca bienestar material desde una especie de moderno despotismo ilustrado. Es decir, aquel que nos aporta capacidades para evitar toda dominación arbitraria sobre nuestras personas $[\ldots]$

En suma, lo que este apretado resumen nos dice es que ningún gobierno cumplirá con los fines de ampliar la libertad si no controla el poder de los grandes intereses económicos y construye rigurosamente, en la medida de sus posibilidades, un Estado democrático de derecho con fuerte desarrollo de aquellas políticas (educación, sanidad y seguridad, ante todo) que contribuyen a generar una ciudadanía no sometida a la dominación arbitraria y capacitada para regir su destino (Villoria Mendieta e Izquierdo Sánchez, 2018, p. 345)

En un Estado social y democrático de Derecho, la Administración ya no es dueña del interés público, sino que está llamada a articular una adecuada intercomunicación con los agentes sociales para definir las políticas públicas. Desde esta perspectiva puede entenderse mejor la función promocional de los poderes públicos, cuya misión es crear un clima en el que los ciudadanos puedan ejercer sus derechos fundamentales y puedan colaborar con la propia Administración en la gestión de los intereses públicos. En este contexto, pienso que estaremos más cerca de un aparato público que oferte servicios de calidad y que promocione los derechos fundamentales de los ciudadanos (RodríguezArana Muñoz, 2017, p. 76)

La noción de buen gobierno constituye uno de los pilares de declaraciones, códigos, etc., emitidas por organismos nacionales e internacionales. Noción polisémica y con referencialidad histórica heterogénea por supuesto. Noción también problemática por cuanto al situarse como horizonte normativo-ideal de los gobiernos efectivos exige, para las burocracias y tecnocracias estatales, 
cristalizar en diseños institucionales, procesos, sistemas de garantías, etc., que no siempre condicen con los principios enumerados. Un buen gobierno no lo puede ser, en las condiciones actuales marcadas por la complejidad social y la sociedad reflexiva — al tiempo que signadas por nuevas tendencias hacia prácticas y conductas irracionales, como pone de manifiesto la actual situación ante las vacunas COVID_- más que acompañado de una buena administración cristalizando en un horizonte normativo más abarcativo: la buena gobernanza (Rodríguez Alba, 3 de junino de 2020). Sin entrar en el detalle de los diseños institucionales, condicionantes tecnológicos, dimensiones de racionalidad práctica, etc., que se precisan para una tal gobernanza - y recordando que la noción de gobernanza alude a la presencia de redes de actores diversos, con lógicas de intereses, poderes y urgencias variadas, pero siempre en un marco institucional que favorece la horizontalidad, colaboración y participación, es central comprender que tras esta noción normativa (buena) y técnica a la vez (gobernanza) está de modo claro la reflexión ética. Una reflexión que tiene niveles diversos y sin duda, en su dimensión práctico-institucional, puede asumir el formato de una ética aplicada.

Autores de diversas épocas, culturas y orientaciones políticas han comprendido como funciones del buen gobierno (Román Masedo, 2020, pp. 168-169): la protección de vidas y bienes de los ciudadanos y el establecimiento de condiciones para el disfrute de ambos; la aplicación de la ley por igual en la búsqueda de la justicia; gobernar para beneficio de la comunidad; el logro del bienestar, entre otras. Referentes como Villoria (2013) sostienen que el buen gobierno conduce a la felicidad, como el malo lo hace al sufrimiento. Lo que de algún modo es avalado empíricamente: estudios de correlación múltiple (Rothstein y Holmberg, 2019) señalan con claridad que los países más corruptos $-\mathrm{y}$ consideramos intuitivamente que la corrupción es indicador de mal gobierno, como la integridad lo es de bueno- - son países con menor sentimiento de felicidad.

Desde un punto de vista institucionalista, para lograr un buen gobierno se precisan (Villoria Mendieta, 2013): diseños institucionales orientados a promover capacidades participativas, de diálogo y colaboración; promover, en el ámbito constitucional, la protección de derechos y libertades fundamentales; incentivar el debate y análisis ilustrado, la igualdad de oportunidades, así como políticas de fondo que desarrollen el estado de derecho, la democracia y el bienestar.

El buen gobierno (Villoria Mendieta e Izquierdo Sánchez, 2018, p. 344) promueve instituciones formales e informales que fomentan la: transparencia y rendición de cuentas; efectividad; coherencia; participación; integridad; objetividad e imparcialidad; y la responsividad. 
De tal modo puede apreciarse que en la operación de un buen gobierno, considerado en los diseños institucionales precisos para el mismo, se ha de proceder con su correlato ineludible: la buena administración. Esta noción ha cobrado relevancia en el derecho comunitario, en la Unión Europea (Rodríguez-Arana Muñoz, 2012). Mediante el mismo se hace referencia a principios clásicos de la administración burocrática — por ejemplo: objetividad, neutralidad, mérito, imparcialidad, etc.—, pero añadiendo el horizonte de las nuevas formas de gestión relacional en las que la ciudadanía no asume un formato pasivo, sino que se constituye como un actor decisorio de la calidad de los procesos de gestión pública. Se precisan pues nuevos principios de trasparencia, rendición de cuentas, confiabilidad, colaboración, apertura, benevolencia, orientación a la dignidad de la persona, etc. A poco que nos fijemos observaremos sin duda que tanto el buen gobierno como la buena administración están preñados de ética, en tanto hacen alusión a principios, valores y normas que trascienden el horizonte puramente pragmático de las reglas de habilidad, prudenciales, técnicas y jurídicas. La idealidad de normas, valores y principios éticos es así definitoria del buen gobierno y la buena administración, sin prejuicio por supuesto que esta idealidad haya de materializarse en diversos formatos normativos, institucionales, formativos, etc.

Ciertamente las nociones de buen gobierno y buena administración, pertinentes en la geometría de ideas que apuntala la noción de buena gobernanza, son nociones complejas que tienen diversas líneas interpretativas. Algunos estudios (Cejudo, Sánchez y Zabaleta, 2009) han destacado cómo en la construcción de conceptos como buen gobierno - y buena gobernanza - se apela a nociones como calidad de la democracia, emergiendo dos grandes ámbitos de problemas. Por un lado problemas teóricos asociados al constructo — se escora la noción de calidad democrática hacia el proceso electoral, obviando la problemática del ejercicio del poder-; pero también problemas metodológicos como la determinación de variables que definen la buena gobernanza (Román Masedo, 2020) — muchas de las mismas orientadas hacia las necesidades de financiación de proyectos por parte de organismos multilaterales como el Banco Mundial—, o el hecho de que se apela a dimensiones que impelen a problemas de causalidad revertida: ¿causa el buen gobierno la calidad democrática o es a la inversa?.

El concepto de buen gobierno tiene una eminente dimensión normativa, mientras que el de gobernanza se orienta más a la medición de prácticas (Aldeguer Cerdá, Abellán López y Pardo Beneyto, 2020). Prácticas de gobernanza que se orientan hacia estándares de calidad (buena gobernanza) en la medida en que junto a los diseños normativo-institucionales del buen gobierno y la 
buena administración, apuestan por los pilares del gobierno abierto (transparencia, rendición de cuentas, colaboración, participación, innovación) y la administración relacional. En esta dirección, así como hay un relativo consenso respecto a que un buen gobierno es un gobierno limitado (Villoria Mendieta, 2018) que potencia la autonomía de personas y agrupaciones, la noción de una buena administración es solidaria de la de administración relacional (Alguacil, 2012). Una administración que apunta hacia la intergeneracionalidad, interterritorialidad y la apertura constante de espacios deliberativos en los que la ciudadanía piensa fines y medios de la gestión pública.

El buen gobierno — por extensión la buena gobernanza - requiere sin duda alguna de una buena administración, una administración que sobre la base de sistemas burocráticos de calidad fomente la imparcialidad necesaria para articular otros valores propios de la democracia, como son la equidad, solidaridad, inclusión, etc. La calidad democrática podrá determinarse empíricamente, con todas las discrepancias que esto suponga, pero en la medida que se articula con el buen gobierno requiere del valor central en la concepción burocrático-weberiana: la imparcialidad (Cejudo, Sánchez y Zabaleta, 2009). Sin duda un campo de problemáticas éticas en sí misma esta construcción: ¿qué relación tiene la imparcialidad administrativa con la equidad social? ¿Es posible sortear los defectos de las múltiples manos burocráticas ineludibles en la organización jerárquica de las administraciones con fines de objetividad, neutralidad e imparcialidad? Si la imparcialidad es un valor central en la construcción de la noción normativa de un buen gobierno: ¿qué lugar tienen las prácticas del cuidado de la diferencia que precisan de la mirada minuciosa y particularista? Y otros tantos interrogantes que sin duda pueden emerger en esta construcción conceptual.

No podemos entrar en estas problemáticas éticas en este lugar. Tan sólo diremos que desde una ética que atienda a la particularidad, la diversidad, las asimetrías, la pluralidad de seres hablantes que no asumen el formato argumentativo más duro — aquello que Marion Young llamara las democracias narrativas (2000) — se precisa sin duda atender a la centralidad de la imparcialidad, pero quizá una imparcialidad situada (Rodríguez Alba, 2019) que aproxime a los imperantes modelos deontológicos y utilitarios —imperantes sin duda en la ética de la administración pública—, paradigmas como el del juicio. Si las burocracias de calidad — determinadas con los estándares usuales al efecto- son condición para el buen gobierno, no es menos cierto que el brazo ejecutivo de la burocracia (el servidor público), así como el decisor público en general, ha de atender a las demandas, reclamos, necesidades, etc., de una sociedad cada vez más compleja. Para tal fin no basta sólo con un proceso burocrático estandarizado que se centre en criterios utilitaristas —el mayor bienestar para el mayor número—, ni 
la supuesta derivación de deberes abstractos al modo deontológico. Apostar por el análisis y tematización ética de la situación sin reducirse a causismo, pero sin anular la especificidad en nombre del principalismo (Ausin, 2011) es central para una ética en la administración pública.

La ética en la administración pública, o por decir de modo más amplio la ética en la gestión pública -ética que atañe a la administración pública como aparato de estado pero también a la dimensión creativa y política - es una disciplina muy antigua (Diego Bautista, 2007), que cristaliza como disciplina académica — apegada al campo de las ciencias políticas y de la administración pública - en los años setenta especialmente (Diego Bautista, 2007; Merino Amand, 2013). Si se la considera como una ética aplicada (Rodríguez Alba, 2019) su presencia puede ser contemplada en una doble dirección: material y formalmente. Como toda ética aplicada nace de las prácticas sociales mismas (Cortina, 1996), en nuestro caso las prácticas de gestión pública en sus dimensiones administrativas y políticas. Materialmente presente pues en dilemas políticos a lo largo de la historia, en leyes, normas, procedimientos administrativos, etc., pero también en modelos de gestión pública con valores diversos (Diego Bautista, 2007). Modelos que ejercitan valores como la neutralidad, imparcialidad, objetividad, etc., del modelo burocrático; la orientación al servicio, la participación, etc., de modelos de Nueva Gestión Pública; o en modelos de gobernanza (Rodríguez Alba, 2019) en la deliberación pública sobre fines, relación fines-medios, etc. Formalmente constituida como dijimos en un amplio repertorio de corrientes, autores, etc. que eclosiona tras los años 70. Manuales como el de Cooper (2001) dan cuenta de la heterogeneidad de temáticas que abarca el campo de estudio de la ética en la gestión pública: rendición de cuentas, responsabilidad, dilemas éticos en la gestión, valores constitucionales, conflictos de interés, etc. Temáticas que han variado a lo largo de la historia. Si olvidar las clásicas problemáticas de la ética en los cargos públicos (Thompson, 1999): las manos sucias democráticas (problema de la legitimidad de los medios respecto a los fines) o las múltiples manos (problema de la responsabilidad en casos de gestión que involucran pluralidad de actores).

La constitución del campo de la ética en la gestión pública es así un tema relevante para una ética que promete convertirse en central en nuestros tiempos y que ha tenido hasta la fecha, especialmente en el ámbito filosófico, poco abordaje. Existen innumerables reflexiones filosóficas sobre la ética en los asuntos públicos, pero las mismas no han logrado a fecha un campo específico de tematizaciones. Las que se han logrado provienen más de campos prácticos como el de la administración pública o las ciencias políticas, así como el derecho por supuesto. Los aportes en los mismos son centrales y fundamentales. ¿Qué puede aportar una tematización filosófica al respecto? 
Por supuesto una pregunta como esta tiene muy diversas respuestas en base a las corrientes de pensamiento, puesto que la filosofía es un campo de por sí polémico, en lo que reside precisamente su centralidad. Pero como campo disciplinar amerita considerarse la ética en la gestión pública desde algún paradigma reflexivo que permita, como escalera wittgensteniana, al menos subirse al andamio desde el que poder divisar una panorámica general de las problemáticas y temáticas éticas involucradas en la gestión pública.

Apoyándonos en la tópica distinción entre ética descriptiva, ética normativa y metaética, y siguiendo la sistematización que autores como Ricardo Maliandi han hecho del campo de estudio de la ética, podemos aventurar algunas consideraciones (Rodríguez Alba, 2019, 2020). La primera de ellas es la consideración de la ética (Maliandi, 2009) como una tematización del ethos, considerando que éste es un fenómeno cultural complejo que involucra dimensiones de carácter individual, grupal (organizacional) y social. Así como la persona física tiene una dimensión ética, también lo tienen organizaciones y sociedades. La ética de las organizaciones puede considerarse una tematización del ethos (Etkin, 2012), orientada a generar buenas prácticas, esto es, a potenciar un círculo virtuoso en los procesos de gestión, impactos, etc. Es más, justo esa tematización ética puede evitar el riesgo de brechas éticas en las organizaciones (Etkin, 2012): unas brechas que inciden en fenómenos perversos como la doble moral, las víctimas del silencio, la rutinización de procesos que conducen a la banalización del mal, etc.

La tematización ética adquiere diversos formatos (Maliandi, 2009): meditaciones, problematizaciones, investigaciones, ensayos, etc. Usa metodologías diversas (Maliandi, 2009): analíticas, fenomenológicas, dialécticas, descriptivas, etc. Considerando la facticidad normativa de la praxis humana (García-Marzá y González Esteban, 2014)—el hecho de que toda acción está regulada por normas técnicas, jurídicas, morales—, la reflexión moral es ciertamente central en la conformación del carácter. Es más, la ruptura de tal facticidad, la conflictividad moral misma - entre normas, principios, valores, actitudes- es un motor fundamental en el desarrollo moral de las personas (Kohlberg 1992; Lind, 2008). En este desarrollo moral los procesos de deliberación (Lind, 2008, 2011) pública son centrales, al punto que permiten el tránsito de una etapa convencional del juicio moral guiada por el acomode a las reglas establecidas — a una posconvencional —orientada hacia principios universalizables-. Del mismo modo que las personas, con la tematización ética, máxime con elementos deliberativos y prudenciales, las organizaciones pueden transitar de una etapa signada por la lógica de lo adecuado — rutinas, hábitos, etc., adquiridos, inconscientes, funcionales, etc.— a una lógica de lo correcto, convertirse en organizaciones postconvencionales (Villoria, 2007). 
En resumen, si la ética pública puede considerarse como una tematización ética del individuo en relación (Muguerza, 2009), una tematización que sin duda exige considerar dicha ética en el terreno de la filosofía política (Rodríguez Alba, 2010) —atendiendo a las corrientes de la misma así como sus supuestos ontológicos, antropológicos y sociológicos (relativos al modelo de acción social que postulan) - la aplicación de la ética tomará en cuenta su vínculo con las prácticas mismas de gestión pública (Rodríguez Alba, 2019). A este respecto un riesgo no menor estriba en centrar la tematización en la reflexión moral espontánea, pues así se cuelan en los diseños normativos e institucionales ideas, sesgos, modelos tácitos, modelos de gestión pública periclitados, incoherencias normativas, prácticas poco eficaces, etc. (Rodríguez Alba, 2020).

Por ir cerrando esta breve nota introductoria. La eficacia de la aplicación de la ética en los procesos de gestión pública exige (Diego Bautista y Rodríguez Alba, 2021) la consideración de múltiples dimensiones —ética cívica, ética organizacional, ética profesional— así como un abordaje integral que suponga una metodología top down conjuntamente con el abordaje colaborativo, multistakeholder, tipo bottom up, de la creación de redes de integridad. Precisa la construcción holística de sistemas éticos integrales (Diego Bautista, 2009) considerando fases en el proceso. Por su parte en el terreno disciplinar la aplicación de la ética — considerando los diversos modelos de aplicabilidad (Rodríguez Alba, 2019) en los que no podemos entrar aquí- resulta de vital importancia para sobreponerse al riesgo de la reflexión moral espontánea que hemos señalado. Al efecto considero de relevancia apostar por lo que denomino el ciclo de aplicación de la ética en la gestión pública (Rodríguez Alba, en Universidad Siglo 21, 3 de junio 2020).

La emergencia de conflictos y dilemas en los procesos de gestión pública es de sobra conocida. Tematizar esta conflictividad es una de las claves de la reflexión ética (Maliandi, 2010, 2012): una ética que no se reduce a un enfoque principalista nomológico, sino que opta por la pluralidad de principios, pero a su vez apuesta por cauces de convergencia. Convergencia que por supuesto nunca será plena, sino más bien una suerte de consensos parciales que permiten conquistar esferas crecientes de universalidad (Rodríguez Alba, 2019). Por supuesto una conflictividad que no evita el antagonismo, pero apuesta por no disolver los conflictos por la vía de hegemonizar uno de los polos en los mismos. No se trata pues en la aplicación de la ética de la derivación de reglas concretas de conducta respecto a principios genéricos de acción, lo que no obsta la importancia normativa de los mismos.

Además, en el diseño de las instituciones y normas éticas mismas se amerita un abordaje que contemple la facticidad normativa, junto con la coherencia y fundamentación, así como la exploración 
de los cauces de razonamiento moral justificativo. Por esto entendemos que la aplicación de la ética, tanto en situaciones problemáticas como en el diseño de infraestructuras éticas, exige considerar elementos descriptivos, normativos y metaéticos.

La ética descriptiva — pegada al análisis de las prácticas éticas en organizaciones, sociedad, etc., mediante el uso de las metodologías propias de las ciencias (neuroética, neuropolítica, ciencias de la conducta, ciencias sociales, historia, etc.) - nos permite comprender la anatomía de los valores, normas y principios. Permite por ejemplo sacar a luz el isomorfismo estructural que hace que se repliquen estructuras normativas de unas instituciones a otras, o que se reproduzcan modos de conducta de unas instituciones sociales a otras. Comprender este isomorfismo es central para el diseño de adecuadas herramientas de gestión ética, así como para incidir en variables de socialización, cultura y clima ético, etc. A su vez, comprender la presencia de lógicas de lo apropiado (Villoria Medieta 2007) ayuda a activar mecanismos normativos e institucionales adecuados para que los principios y valores permeen hacia las prácticas efectivas.

La ética normativa — anclada al proceso de análisis y fundamentación de los diseños normativos e institucionales, tanto en su vínculo con el derecho como con los estándares y herramientas de gestión, por ejemplo la gestión de riesgos de integridad - potenciará que los diseños y aplicación concreta en el seno de una institución, nivel de gobierno, etc., esté amarrada de modo tal que no redunde en pura declaración de principios sin vínculo alguno con el sistema normativo que permite la sanción y regulación efectiva de la conducta. Al mismo tiempo el análisis normativo permitirá localizar estándares éticos apropiados a la institución, función pública, etc.

Finalmente la metaética — análisis del lenguaje, razonamiento y justificación moral— permitirá comprender las dimensiones comunicacionales y dialógicas necesarias para que los procesos participativos y colaborativos necesarios en la aplicación de la ética no terminen por estar alejados de la experiencia moral de los stakeholders involucrados. Al mismo tiempo, usando herramientas de análisis de lenguaje mediante, por ejemplo, portales de consultas, quejas, etc., permitirá comprender elementos importantes en la reflexión moral de los diversos stakeholders con los que interactúan las instituciones y cargos públicos. El análisis metaético permite aceitar y ajustar los diseños y estrategias de gestión ética, máxime si se contemplan en el marco de un adecuado abordaje de los procesos comunicacionales que incentivan la colaboración, participación e innovación pública. 
Un ciclo virtuoso de aplicación de la ética en el diseño de infraestructuras y sistemas éticos puede ser abordado en momentos o fases, de modo parcial y conforme siempre a las expectativas y lineamientos en materia de políticas éticas.

En síntesis, el ciclo de aplicación de la ética puede comprenderse como un horizonte metodológico para eficaces infraestructuras éticas (Rodríguez Alba 2020). Entre tanto los modos de aplicación de la ética permitirán abordar situaciones de conflictividad moral o de aplicación de estándares, normas y principios éticos a situaciones concretas de gestión pública.

Un abordaje sistemático tal por supuesto no es factible en un número monográfico, si bien es muy de agradecer que el CEDEA (Centro de Éticas Aplicadas) de la Universidad de Chile pueda sumar estos espacios de reflexión y sin duda felicitar, agradeciendo con encono, esta iniciativa en la revista ETHIKA+. Me atrevo a decir que son pocos los números monográficos dedicados a la ética en la administración pública, máxime en nuestro ámbito hispanohablante. Y oso incluso a alentar a quienes lean este número que se animen a incentivar estos espacios, así como potenciar dinámicas y espacios académicos orientados a generar redes de tematización ética. En este número hemos contado con reflexiones que abordan elementos de ética descriptiva, con retazos de abordaje desde la ética normativa en su dimensión específicamente jurídica. Detallo a continuación — siguiendo el orden que es el de aprobación - los trabajos, animando a la lectura minuciosa de los mismos y recordando que dichos trabajos han sido objeto de un riguroso proceso de evaluación de pares. En todo el proceso los autores han sostenido una actitud coherente con principios y valores ineludibles de la ética académica e investigativa.

Rodolfo Elizalde y Mayra Sánchez realizan una aproximación comparativa entre México, Chile y Colombia con el fin de explicitar analogías y diferencias en el abordaje de las infraestructuras normativas de la ética, considerando que estos países tienen tradiciones heredadas en lo filosófico en especial las teorías del contrato social - y que de modo afín han sufrido los procesos de trasformación conocidos como neoliberalismo. A pesar de que Chile y Colombia consolidan una forma estado centralista, a diferencia de la federal de México, conforman normativas éticas con valores afines. En su trabajo - La ética pública en México, Chile y Colombia. Un estudio de derecho comparado- los autores señalan valores comunes y valores diferenciales en estos países. El análisis comparado de principios éticos sin duda es una apuesta central para la consideración de la ética en la gestión pública.

El trabajo de Roxana Andrade - Tecnificación y despersonalización de la muerte vía su racionalización: un análisis desde la deontología y el utilitarismo - entra de lleno en la consideración ética de la gestión de la 
muerte en la crisis sanitaria provocada por el Covid. Como señala la autora la gestión de la muerte ha sido considerada un indicador de gestión de gobierno ante la crisis sanitaria. Lo interesante de este artículo estriba en cómo saca a relucir la tensión entre una perspectiva utilitarista — que apuesta por la protocolización de los rituales fúnebres con el objetivo de salvar la mayor cantidad de vidas- y otra deontológica — apuntalada sobre la noción de una dignidad humana que cristaliza en la singularidad del rito fúnebre- - La autora propone en esta tensión optar por diseños intermedios en las políticas públicas, orientados a la consideración de la diversidad cultural. Este trabajo supone así una problematización sobre una de las corrientes más extendidas en la ética administrativa, la corriente utilitaria.

Agustín Ferraro y Gustavo Fondevita abordan un tema central para la ética en la administración pública, y en general en la teoría de la administración pública: la interfaz entre política y administración. El interrogante central de su trabajo (¿Puede la burocracia tomar decisiones?) ha sido explorado desde diversas aristas. Los autores abordan las problemáticas inherentes a los organismos públicos independientes — como por ejemplo el mexicano Instituto Federal Electoral— y su contribución a la legitimidad democrática y ética de los gobiernos. A propósito en La dificultad contramayoritaria de las burocracias públicas. Democracia, ética y legitimidad institucional en América se exploran las fuentes de legitimidad (autonomía, reputación, apertura, participación y resultados) que pueden coadyuvar en el enriquecimiento de los gobiernos, superando la usual reducción de la legitimidad a la confrontación partidaria.

Oscar Diego — La ética en las constituciones y tratados internacionales. Fundamentos desde la teoría aristotélica de la virtud - propone considerar el análisis ético de las constituciones atendiendo a la teoría aristotélica de la virtud. De este modo, recuperando documentos internacionales relativos a los valores que definen un buen gobierno, Oscar Diego estima que es posible retomar la noción de un estado ético, así como la valoración de constituciones justas e injustas, siendo el eje central que articula las mismas la oposición entre democracia y oligarquía. El ejercicio de las virtudes en legisladores y gobernantes resulta clave en este proceso de conformación de un estado ético para el autor.

En La ética de gobierno en tiempos de pandemia en Argentina Federico Saettone nos sitúa ante uno de los tópicos centrales de la ética pública en su vertiente descriptiva. Tras establecer la distinción entre control legislativo y control parlamentario, el autor analiza cómo el predominio presidencialista en América Latina, y en Argentina en especial, da pie a una suerte de, podríamos decir, reducción del control parlamentario a control legislativo, existiendo una tendencia a la aprobación tácita de 
instrumentos legislativos como los decretos de necesidad y urgencia. Federico liga esta situación a los diseños institucionales, pero también explora en su trabajo — considerando la priorización de decretos de necesidad y urgencia en los casos de crisis sanitaria como el Covid — a problemáticas asociadas al liderazgo presidencial.

El número cierra con el trabajo de José María Hernández Losada —Ética pública y resiliencia democrática- En el mismo el autor aborda la innovadora noción, en el terreno de la gestión pública, de la resiliencia como elemento que permite una nueva anatomía de conexiones entre la ética pública y el orden democrático. A propósito de las fallas en el liberalismo triunfante, patentes en diversos frentes, José María propone nuevas figuras de democratización del espacio público — colonizado y abatido por las transformaciones tecnológicas, en especial las impactadas en el mundo comunicacional de las redes sociales - mediante una geometría de virtudes públicas que cristalizan en la resiliencia. La esfera pública amerita cultivar nuevas formas de racionalidad práctica, habida cuenta de las amenazas hacia el pluralismo por parte de las transformaciones comunicacionales.

Los autores entran así en tópicos centrales relativos a la ética pública —valores constitucionales, ética parlamentaria, virtudes públicas, dilemas en la gestión pública, ética administrativa-, a la ética aplicada a casos concretos y temas específicos vinculados a un buen gobierno. En efecto, un buen gobierno, como hemos señalado al comienzo, ha de orientarse a la autonomía de la persona y de lo social, a potenciar la trasparencia, la rendición de cuentas, la apertura, la colaboración, etc. En sus trabajos se destilan reflexiones que permiten visualizar tematizaciones concretas al respecto del buen gobierno, la buena administración y los procesos de gobernanza pública.

En este número contamos también con un aporte de reseñas de considerable valor, precisamente porque nos ponen ante un rico material de estudio en el campo. Estas reseñas son pues un valioso aporte para incentivar la profundidad en estos temas. Recuperamos muy someramente las mismas.

Nicole Oré Kovacs nos trae a lectura la obra de Gonzalo Gamio Gehri El experimento democrático. Según Nicole esta obra nos refresca la necesidad de una pedagogía deliberativa que fortalezca valores como el falibilismo pragmático, centrales hoy en día para combatir las tendencias antidemocráticas y autoritarias imperantes en Perú, y en el mundo podríamos incluso soslayar. Diego Ticchione Sáez nos presenta el trabajo Lecciones aristotélicas para la administración pública, de Edgar Espinal Betanzo. Un trabajo que incide en la centralidad de la prudencia en las buenas elecciones que han de orientar las decisiones de los agentes estatales. Oscar Morales Bravo apuesta por problematizar una 
noción central en la ética pública, como es la noción de mérito. En efecto potenciar la ética en los procesos de gestión pública exige sistemas burocráticos que, sin dejar de lado el mérito, tengan en cuenta la problemática social que los mismos suponen (Rodríguez Alba y Sesma, 2018). En su reseña Oscar Morales acierta a rescatar la obra de Michael Sandel — The Tyranny of the Merit - analizando cómo tras la retórica del mérito se esconde un cóctel ideológico tóxico para los menos favorecidos, por la vía de la legitimación de una tecnocracia que busca naturalizar su posición social. Sofía Pezoa Stopello nos trae a lectura la obra Evil Online, obra de Dean Cocking y Jeroen Van den Haven. Según la lectura de Sofía esta obra incide en algo que por más sabido no deja de ser central: las redes sociales potencian una falsa autonomía e integración. Más allá de los aspectos delictivos, las redes, aunque no responsables de los males que aquejan nuestras sociedades, sin duda tienen gran poder para amplificarlos. Para finalizar, Laura Gallardo Nevado reseña el trabajo de Silvia Federici, El patriarcado del salario. Considerando central la crítica feminista al marxismo, por cuanto oculta el trabajo reproductivo sin problematizar los espacios de subdesarrollo capitalista presentificados en los roles de género, Laura Gallardo destaca la propuesta de Silvia Federici relativa a una política de lo común. Política que emerge de la revalorización de los conocimientos y tecnologías locales, entre otros factores. Sin duda un gran aporte para las tematizaciones éticas que se buscan en el campo.

Los escorzos de tematización ética que en este número asoman podrán resultar contingentes. Otros editores hubieran avalado otros trabajos. Pero como el campo es tan amplio los presentes permiten visualizar ejes centrales en la definición de un buen gobierno, desde aristas que inciden en la poliédrica consideración de la ética aplicada a la gestión pública. De tal modo asoman entre las páginas de este número reflexiones de mucho interés para la ética parlamentaria, la ética gubernamental, la ética cívica, la tematización ética en los procesos constituyentes, etc.

No quisiera dejar de presentar este número sin algo fundamental. Ciertamente la ética ha de evitar la moralización, pues la misma diluye la anatomía moral del espacio público como lo pudiera hacer la cínica consideración realista. Pero no oculto que hay tres principios que pudieran devenir en una consideración materialista y spinoziana de producción de lo común humano- de vital importancia para nuestras plurales y complejas relaciones. Fortaleza para resistir los embates de un sistema mundo cada vez más hostil con lo público. Firmeza para apuntalar las conquistas sociales y éticas de la racionalidad humana, plural, dinámica y cada vez más austera. Generosidad para compartir los logros y recibir la plural condición humana en su capacidad creativa. De los tres creo que es testigo la labor del CEDEA (Centro de Éticas Aplicadas) al posibilitar este monográfico peculiar. Es de 
agradecer mucho esta encomiable tarea. Al efecto no quiero dejar de hacer mención especial al trabajo de Nicolás Rojas Cortés, pues todo el trabajo minucioso de edición ha sido coordinado por él. Sin duda Nicolás ha tenido la generosidad de acompañar a cada uno de los autores y evaluadores por par ciego que avalan estos trabajos. Gracias también por su firmeza al sostener la calidad del proceso. Y sin duda amerita reconocer su fortaleza en poder enseñarme de todo el proceso. 


\section{REFERENCIAS BIBLIOGRÁFICAS}

Aldeguer Cerdá, B., Abellán López, Ma A., y Pardo Beneyto, G. (2020). Estrategias y arreglos institucionales para la efectividad y realización del buen gobierno. Una aproximación desde la perspectiva del caso español. En A. Hernández Mendoza. y O. Diego Bautista, Elementos para la edificación de un buen gobierno (pp. 135-158 ) INAP (Instituto Nacional de Administración Pública)

Alguacil, J. (2012). Administración relacional. Eunomía. Revista de cultura para la legalidad, (2), 152-160.

Ausin, T. (2011). Ética en las Administraciones. Eunomía. Revista de cultura de la legalidad (1), 141-147.

Camps, V. y Cortina, A. (2009). Las éticas aplicadas. En C. Gómez y J. Muguerza (Eds.), La aventura de la moralidad $\left(2^{\circ}\right.$ reimpresión). Alianza Editorial.

Cejudo, G., Sánchez, G. y Zabaleta, D. (2009). El (casi inexistente) debate conceptual sobre la calidad del gobierno. Politica y gobierno, XVI(1), 115-156.

Cooper, T. L. (ed.) (2001). Handbook of Administrative Ethics. Marcel Dekker, Inc.

Cortina, A. (1996). El estatuto de la ética aplicada. Hermenéutica crítica de las actividades humanas. Isegoría, (13), 119-134.

Diego Bautista, O. (2007). La ética en la gestión pública: fundamentos, estado de la cuestión y proceso para la implementación de un sistema ético integral en los gobiernos. (Tesis doctoral). Universidad Complutense de Madrid.

Diego Bautista, O. (2009). Ética para corruptos. Desclée de Brouwer.

Diego Bautista, O. y Rodríguez Alba, J. (2021). El Sistema Ético Integral (SEI). Un modelo para prevenir la corrupción. En O. Diego Bautista (coordinador), Quinientos Años de Corrupción. ¿Cómo llegamos hasta aquí? ¿Cómo salimos de aquí? Tirant Lo Blanch

Etkin, J. (2012) Brechas éticas en las organizaciones. Sistemas virtuosos y tramas perversas. Cengage Learning

García-Marzá, D., González Esteban, E., (2014) Ética. Universitat Jaume I.

Kohlberg, L. (1992) Psicología del desarrollo moral. Descleé de Brower

Lind, G. (2008) La moral puede enseñarse. Ed. Trillas

Lind, G. (2011) Promoviendo las competencias morales y democráticas: expresarse y escuchar a los otros. Postconvencionales, (3), 26-41. 
Maliandi, R. (2009) Ética: conceptos y problemas. Biblos.

Maliandi, R. (2010) Ética convergente. Tomo I. Fenomenología de la conflictividad. La Cuarenta.

Maliandi, R. (2012). Lo óptimo es enemigo de lo mejor. Ensayo de metacrítica a la crítica de Guillermo Lariguet. En A. Damiani, G. Lariguet, y R. Maliandi, Ética y conflicto. Un diálogo filosófico sobre la ética convergente (pp. 189-269). Universidad Nacional de Lanús.

Mansilla, H.C.F. (1982). Las teorías clásicas sobre el buen gobierno y su significación actual. Revista de Estudios Politicos (Nueva Época), (29), 163-173

Merino Amand, F. (2013). El reconocimiento como fundamento de una ética de la función pública. (Tesis doctoral). Universidad de Valencia

Muguerza, J. (2009). Ética pública, derechos humanos y cosmopolitismo. En C. Gómez y J. Muguerza, La aventura de la moralidad. Paradigmas, fronteras y problemas de la Ética. ( ${ }^{\circ}$ reimpresión). Alianza.

Rodríguez Alba, J. (2010). Ideología y política en la ética pública. La cuestión del Estado ético. En L. Peña, T. Ausín, y O. Diego (Eds.), Ética y servicio público (pp. 269-300). Plaza y Valdés

Rodríguez Alba, J. (2019). Ética aplicada a la gestión pública. Elementos programáticos y formativos desde la experiencia argentina. (Tesis doctoral) UNED (Universidad Nacional de Educación a Distancia).

Rodríguez Alba, J. (2020). La aplicación de la ética en el diseño de infraestructuras éticas para las instituciones públicas. Reflexiones sobre casos argentinos. En D. Vilcher. (coordinadora), Códigos y preceptos éticos (pp. 157-190). INAP

Rodríguez Alba, J. y Sesma, L. J. (2018). El mérito y las competencias éticas en la profesionalización de la función pública: el caso de Córdoba, Argentina. En J. M. Canales Aliende, J y A. Romero Tarin, Estudios sobre la nueva cultura y valores del empleo público (pp. 107-172). Editorial Bosch

Rodríguez-Arana Muñoz, J. (2012). El derecho a la buena administración en las relaciones entre ciudadanos y administración pública. Anuario da Facultade de Dereito da Universidade da Coruña, (16), 247-274.

Rodríguez-Arana Muñoz, J. (2017). La ética pública constitucional y la buena administración. Revista de Administración Pública, LII(3), 67-87.

Román Masedo, L. (2020). Buen gobierno y transparencia. En B. Aldeguer Cerdá y G. Pastor Albaladejo, Democracia, gobierno y administración pública contemporánea (pp. 167-190). Tecnos. 
Rothstein, B. y Holmberg, S. (2019). Correlates of Corruption QOF (The Quality of Government Institute) Department of Political Science University of Gothenburg, https://www.gu.se/sites/default/files/2020-05/2019 9 Holmberg_Rothstein.pdf

Thompson, D. E. (1999). La ética política en el ejercicio de los cargos públicos. Gedisa.

Universidad Siglo 21. (3 de junio de 2020). Ética pública y mejor Estado [Archivo de Vídeo]. Youtube. https://www.youtube.com/watch?v=eD8lqlT8fRI\&ab_channel=UniversidadSiglo21

Villoria Mendieta, M. (2007). Ética posconvencional e instituciones del servicio público. Reis: Revista española de investigaciones sociológicas, (117), 109-142.

Villoria Mendieta, M. (2013). El buen gobierno, entra la integridad institucional y la innovación democrática. Revista Democracia y Gobierno Local, (20), 5-11

Villoria Mendieta, M. (2018). Los sistemas de integridad en las organizaciones: una reflexión desde el enfoque institucionalista del buen gobierno. En J. Rodríguez Alba y G. Lariguet (Comp.), Gobierno abierto y ética. Universidad Nacional de Córdoba

Villoria Mendieta, M., e Izquierdo Sánchez, I. (2018). Ética pública y buen gobierno. INAP-Tecnos

Young, I. M. (2000). La democracia y “el otro”: más allá de la democracia deliberativa. Revista jurídica de la Universidad de Palermo, (1), 41-55. 